\title{
Community medicine: A second chance?
}

The new specialty of community medicine was established in 1974 to bring together into a single discipline those doctors who had previously worked in public health and medical administration. It also provided for their successors a single postgraduate training programme and career structure. Now, six years later, it faces a serious decline in numbers unless recruitment is doubled immediately. That is the main finding of the recent report of a joint working party representing the profession, the Department of Health and Social Security, and the Welsh Office. ${ }^{1}$ How has such a crisis developed so quickly?

The main responsibilities envisaged for community physicians were set out in chapters III and IV of the Hunter Report in $1972 .^{2}$ These were seen as management team duties, child health, liaison with the social services, environmental health, capital building, medical personnel, medical information services and research, and health-care planning. By bringing the doctors responsible for the health of the population as a whole on to the centre of the stage, creating an up-to-date training programme for them with closer links with the universities, and giving them the standing, remuneration, and awards of clinical consultants, the hope and belief was that a solution had been found to the problems of recruitment, morale, and quality which had been evident in the past.

As this latest report points out, events have unfortunately turned out otherwise. There have never been fewer than 100 vacancies in the establishment of community physician posts, and though the latest information shows some improvement, recruitment is inadequate and wastage during training high. The figures for the projected decline in the number of specialists given in the report take no account of any possible effects of the latest reorganisation, which seems likely to lead to a number of additional early retirements and may, therefore, further deplete the ranks of the specialty.

Many of the events which have contributed to this depressing state of affairs have been outside the control of community physicians. In particular, community medicine came to be associated, unfairly, with the bureaucratic hypertrophy of the reorganisation of the Health Service in 1974. It was particularly unlucky that a specialty in which health service planning is a major function should have come into being at the beginning of a profound economic recession which swept away all but the most urgent plans. Furthermore, district community physicians have had to work in professional isolation without a colleague in the same discipline close at hand (an arrangement frowned on in other specialties) and have often had inadequate statistical and even secretarial support.

The 28 recommendations ( $\mathrm{p} 886$ ) cover much ground, including suggestions about the job itself as well as recommendations about recruitment and training. Isolation could be prevented, says the report, by setting up local departments of community medicine containing more than one specialist, but the geographical level at which these should function is not made clear. Adequate support must be provided urgently for community physicians where this is lacking, and the content of the job should be made more flexible by abolishing the designa- ted specialist posts, by permitting private practice (in the sense, for example, of providing advice on the organisation of health services to private organisations), and by encouraging those with the appropriate inclination and skills to engage in clinical practice. The last of these recommendations is particularly interesting because it represents a reversal of previous official policy. A recent survey of the views of community physicians in training shows that the issue is controversial but that most would welcome an option to practise. ${ }^{3}$

So far as the key issue of recruitment is concerned, the report considers that training should generally begin between five and 15 years after registration-that is to say, later than is the case for about half the doctors entering training at present. ${ }^{3}$ The pay of trainees should be increased to a level comparable to that received by trainees of an equivalent level of seniority in the clinical specialties.

One of the most interesting features of the report is the attention it gives to providing for the needs of entrants to community medicine in mid-career. Many of the problems which the community physician meets require a maturity of judgment which most people achieve only after considerable experience. Provided such recruits come to community medicine with a record of success rather than failure in their previous fields they will improve the credibility of the specialty as a whole. The report also makes sensible suggestions about special training programmes for mature entrants and for practitioners who, owing to their domestic responsibilities, will wish to take part-time training.

Doctors and the public are just beginning to realise the importance in the last 100 years of the work of medical men and women whose primary interest has been the improvement of the health of the population as a whole. The 1974 reorganisation conferred on them, for the first time, the advantage of a position on the key committees where health policy ought to be decided. But has this opportunity been taken and have the energies of community physicians been correctly directed? The problem has been and remains to ensure that their career opportunities meet their deeply felt aspirations as doctors by making maximum use, for example, of their understanding of the natural history of disease and the opportunities that exist to prevent it. ${ }^{4}$ Do the roles listed for the community physician in the Hunter Report really meet this prescription? Where does the function of the community physician end and that of his colleagues on the district management team begin? In the answers to fundamental questions such as these-which the joint report does not attempt to discuss-lies the key to the future of scale and quality of recruitment to community medicine.

1 Joint Working Group. Recruitment to community medicine. London: HMSO, 1980.

2 Department of Health and Social Security. Report of the Working Party on Medical Administrators. London: HMSO, 1972. (Hunter Report.)

3 Acheson ED. Clinical practice and community medicine. $\mathrm{Br} \mathrm{Med} \mathfrak{F}$ 1979 ;ii:880-1.

4 Parry KM, Zealley HE. Community medicine: a sense of direction. $\mathrm{Br}$ Med f 1980;280:1193-4. 